\title{
Construção e Estrutura Fatorial de uma Escala de Polidez Infantil
}

\author{
Isadora Ferreira Primo Moreira ${ }^{1}$ (B) \\ Universidade Tuiuti do Paraná, Curitiba-PR, Brasil \\ Murilo Ricardo Zibetti (D) \\ Universidade do Vale do Rio dos Sinos, São Leopoldo-RS, Brasil \\ Paula Inez Cunha Gomide (i) \\ Universidade Tuiuti do Paraná, Curitiba-PR, Brasil
}

\section{RESUMO}

O objetivo deste estudo foi desenvolver e avaliar parâmetros psicométricos da Escala de Polidez Infantil (EPI) nas versões infantil, para genitores e para professores. Inicialmente foi apresentado o desenvolvimento e a avaliação da compreensão dos itens da EPI. Posteriormente, foram investigadas evidências de validade dessas versões por meio de suas estruturas fatoriais. Nessa etapa, participaram 146 crianças (74 meninos) com média de 8,99 anos de idade $(D P=1,46)$ e de 4,10 anos de estudo $(D P=1,36)$. Também responderam os genitores (136 mães e 88 pais) e os professores $(n=22)$ dessas crianças. $\mathrm{Na}$ análise fatorial exploratória, a solução mais adequada nas três versões continha dois fatores (polidez moral e polidez convencional). As versões dos genitores e dos professores apresentaram índices de ajuste e de fidedignidade ômega mais adequados, sendo que escala infantil precisará de ajustes. Por fim, apresentou-se uma alternativa viável para mensuração da polidez precursora do comportamento moral.

Palavras-chave: testes psicológicos; análise fatorial; comportamento infantil; psicometria; polidez infantil.

\section{ABSTRACT - Construction and Factorial Structure of an Infant Politeness Scale}

The aim of this study was to develop and evaluate psychometric parameters of the child, parent and teacher versions of the Escala de Polidez Infantil (EPI - Infant Politeness Scale). Initially, the development and evaluation of the understanding of the EPI items was presented. Next, the validity of these versions was investigated through their factorial structures. In this stage, 146 children (74 boys) with a mean of 8.99 years of age $(S D=1.46)$ and 4.10 years of study $(S D=1.36)$ participated. The parents $(136$ mothers and 88 fathers $)$ and the teachers $(n=22)$ of these children also responded. In the exploratory factor analysis the most adequate solution for the three versions contained two factors (moral politeness and conventional politeness). The parent and teacher versions presented more adequate fit and omega reliability indices, while the child version will need adjustments. The scale presents a viable alternative for measuring the politeness precursor of moral behavior.

Keywords: psychological tests; factor analysis; child behavior; psychometry; childhood politeness.

\section{RESUMEN - Construcción y Estructura Factorial de una Escala de Cortesía Infantil}

El objetivo de este estudio fue desarrollar y evaluar parámetros psicométricos de la Escala de Cortesía Infantil (ECI) en versiones infantiles, para padres y para maestros. Inicialmente, se presentó el desarrollo y la evaluación de la comprensión de los ítems de la ECI. Posteriormente, fueron investigadas evidencias de validez de estas versiones por medio de sus estructuras factoriales. En esta etapa participaron 146 niños (74 varones) con una media de 8,99 años de edad $(D S=1,46)$ y de 4,10 años de estudio $(D S=1,36)$. También respondieron los genitores (136 madres y 88 padres) y los maestros $(n=22)$ de estos niños. En el análisis factorial exploratorio, la solución más adecuada en las tres versiones contenía dos factores (cortesía moral y cortesía convencional). Las versiones de los genitores y de los maestros presentaron índices de ajuste y de confiabilidad omega más adecuados, siendo que la escala infantil necesitará ajustes. Por último, se presentó una alternativa viable para medir la cortesía precursora de la conducta moral.

Palabras clave: tests psicológicos; análisis factorial; conducta infantil; psicometría; cortesía infantil.

Os seres humanos aprendem formas de relacionar-se consigo mesmo e com outras pessoas, de acordo com as contingências nas quais estão inseridos, com os modelos que observam e com as regras que seguem (Gehm, 2013). As interações entre o indivíduo e seu ambiente contribuem para a formação de um padrão de comportamento, que pode ser moral ou antissocial. Os comportamentos antissociais incluem respostas que podem comprometer negativamente as relações (Del Prette \& Del Prette, 2008). Já o comportamento moral abrange respostas como oferecer ajuda, ser polido, conversar, demonstrar empatia, cooperar, respeitar, entre outros, e

${ }^{1}$ Endereço para correspondência: Travessa Pinheiro Machado, 53, Centro, 85505-060, Pato Branco, PR. Tel.: (46) 99127-5182. E-mail: isadoraprimo@hotmail.com Artigo derivado da Dissertação de mestrado de Isadora Ferreira Primo Moreira com orientação de Paula Inez Cunha Gomide, defendida em 2018 no programa de pós-graduação Psicologia Forense da Universidade Tuiuti do Paraná. 
tem como função contribuir com a qualidade e efetividade das relações (Gomide, 2010).

O comportamento moral pode ser considerado como inibidor do comportamento antissocial (Gomide, 2010; Gomide, Mascarenhas, \& Rocha, 2017). A moral é aprendida na infância, assim como a maior parte dos comportamentos e, uma das formas de ensiná-la, é por meio da polidez (Comte-Sponville, 2009; Gomide, 2010; La Taille, 2001). Define-se polidez como uma classe de comportamentos que abrange as subclasses de cumprimentar, despedir-se, agradecer, solicitar um favor, solicitar licença, elogiar e desculpar-se (Comte-Sponville, 2009; Gomide et al., 2012; La Taille, 2001). A polidez é aprendida e reforçada no repertório infantil, sobretudo por meio das práticas parentais positivas (Dishion \& Mcmahon, 1998; Falcke, Rosa, \& Steigleder, 2012; Gomide, 2006; Patias, Siqueira, \& Dias, 2012, 2013; Stattin \& Kerr, 2000) e das interações no ambiente escolar (Löhr, 2003; Melo \& Silvares, 2003).

Tsakona (2016) aponta que crianças com três anos já exibem alguns padrões de polidez em seu discurso. No momento em que atingem a idade pré-escolar parecem ser capazes de ajustar a delicadeza de seu discurso a cada contexto, mesmo que tais habilidades possam ainda não ser idênticas às dos adultos. Nesse sentido, familiarizar as crianças com a polidez pode contribuir para o desenvolvimento da solidariedade e de ações que favoreçam a ocorrência de sentimentos subjacentes à moral, como a empatia e a generosidade.

Nesse sentido, a polidez é considerada por ComteSponville (2009) como a entrada para as virtudes. Todavia, o mesmo autor designa a polidez como uma pré-virtude, pois uma virtude não poderia ser a origem de outras. Ou seja, a polidez é um dos primeiros conjuntos de comportamentos ensinados às crianças, que denota regras de um bom convívio social, mas que pouco valor moral tem em si mesma. Se uma criança aprende a dizer "obrigado", por exemplo, não significa que tenha aprendido o que é gratidão. Contudo, tal ensinamento pode favorecer a exposição da criança às contingências que produzam respondentes como a gratidão e respeito por quem the auxiliou; da mesma forma, ensinar uma criança a desculpar-se pode favorecer a ocorrência do sentimento de culpa e, posteriormente, do comportamento de reparação de dano.

Gomide (2010) denomina de polidez convencional a que possui apenas a estética como função. Essa forma de polidez diz respeito a comportamentos verbais emitidos (agradecer, cumprimentar, pedir licença etc.) os quais não são necessariamente sinceros, mas que, ainda assim, facilitam as relações. A polidez convencional é mantida por reforçamento arbitrário, geralmente proveniente do reforço social dos pais. É quando a criança cumprimenta alguém porque os pais solicitaram e, posteriormente, elogiaram. Contudo, há ainda a polidez moral, a qual está relacionada aos comportamentos que expressam respeito. É mantida por reforçamento natural, quando as consequências da própria interação social, - e não mais dos pais -, passam a aumentar a probabilidade do comportamento. É quando a criança cumprimenta alguém e, dessa forma, produz relações agradáveis que não produziria sendo impolida. É difícil distinguir ambas, haja vista serem semelhantes em topografia, mas diferenciadas pelas consequências que produzem, as quais nem sempre ficam explícitas por meio de observação. No entanto, é possível supor que classes de comportamentos (e.g., cumprimentar) sejam utilizados mais frequentemente de maneira mais estética, enquanto outras classes de maneira mais ética (e.g., desculpar-se). Portanto, esses comportamentos, quanto classificados pelo uso mais frequente, poderiam representar a polidez convencional e moral.

Nesse sentido, a avaliação da polidez é uma tarefa complexa e poucos instrumentos têm sido desenvolvidos para sua avaliação. Por exemplo, desenvolvida sob um ponto de vista da teoria pragmática, a escala de Polidez Absoluta e Relativa indica que há dois níveis de avaliação de uma mensagem (Leech 1983 citada por Leech, 2007). O nível absoluto envolve a avaliação exclusivamente da mensagem sem considerar o contexto, ou seja, por si só a utilização de determinadas palavras pode ser avaliada como polida ou não. Por outro lado, a nível relativo envolve essa avaliação do contexto em que é emitida (Leech 1983 citada por Leech, 2007). Essa forma de avaliação tem sido utilizada no Brasil, mas principalmente para avaliação de mensagens específicas ocorridas na comunicação (Esteves, 1998).

Instrumentos para avaliação da polidez oriundos da observação comportamental e utilizando propriedades psicométricas são bastante raros, como foco em crianças, ainda mais. Isso não significa que ela não seja avaliada de forma indireta por instrumentos que avaliam construtos próximos a polidez, como a gentileza (Binfet, Gadermann, \& Schonert-Reichl, 2016). Assim, a elaboração e validação de uma escala de polidez infantil justifica-se pela contribuição para a mensuração dessa classe de comportamentos e, por conseguinte, na compreensão do processo de aprendizagem do comportamento moral. Além disso, a partir dessa ferramenta pode-se planejar programas que visem a implementação de ações para desenvolvimento de repertórios comportamentais deficitários para o comportamento moral. Ou seja, a promoção de programas de prevenção e intervenção, visando o desenvolvimento do comportamento moral e a redução de comportamentos antissociais (Del Prette \& Del Prette, 2008; Gomide, 2010).

Nesse sentido, o presente estudo teve por objetivos desenvolver uma medida de polidez infantil e obter dados de precisão e validade dessa medida. Para contemplar esses objetivos, a descrição do método e os resultados serão apresentados em dois estudos: I) Desenvolvimento e avaliação da compreensão dos itens da EPI; e II) Obtenção de dados de precisão e análise fatorial exploratória das três versões do instrumento. Essa medida foi denominada Escala de Polidez Infantil (EPI) construída em três versões que são respondidas respectivamente pela própria criança, pelos seus progenitores (pais e mães) e pelos seus professores. 


\section{Estudo 1: Desenvolvimento e Avaliação da Compreensão dos Itens da EPI}

A elaboração dos itens da EPI pautou-se na definição de polidez como sendo uma classe de respostas que abrange os comportamentos verbais de cumprimentar, agradecer, solicitar um favor, solicitar licença, desculpar-se, despedir-se e elogiar. A elaboração e seleção dos comportamentos que compuseram os itens da escala foram baseados nos seguintes autores: Comte-Sponville (2009), Del Prette e Del Prette (2008), Gomide (2010), Gomide et al. (2012), Netto e Gomide (2016), Falcão e Bolsoni-Silva (2016). Particularmente, os cinco primeiros comportamentos foram selecionados considerando as virtudes relacionadas ao desenvolvimento do comportamento moral (Gomide, 2010). Para os comportamentos supracitados, utilizou-se a operacionalização relativa à observação de comportamentos de polidez em sala de aula em estudo conduzido por Gomide et al. (2012). Já os comportamentos de despedir-se e elogiar foram incluídos na definição de polidez do presente estudo uma vez que Falcão e Bolsoni-Silva (2016) atribuem a ambos a função de civilidade, que é uma das funções da polidez.

A partir desses comportamentos foram elaborados 14 itens expressos na forma de declarativas que representavam comportamentos indicativos de polidez, sendo dois itens para cada um dos comportamentos citados anteriormente. Um dos itens referia-se ao comportamento emitido em relação às pessoas conhecidas e o outro item, ao comportamento emitido em relação a desconhecidos ou pouco próximos. A justificativa para tal distinção reside na compreensão de que a interação com pessoas conhecidas é mais frequente, porém, a habilidade de comportar-se de forma educada com pessoas desconhecidas também constitui uma forma de polidez. Do ponto de vista teórico é esperado que alguns grupos de comportamentos sejam mais utilizados de maneira convencional (e.g., cumprimentar, despedir) e outros de maneira moral (e.g., agradecer, desculpar). Apesar disso, mesmo utilizando a definição de polidez de Gomide (2010) que contempla a polidez convencional e moral, a criação dos itens foi definida a partir de classes de comportamentos que não foram a priori classificadas nessas categorias, justamente para verificar a emergência dos dados na análise fatorial exploratória (Estudo 2).

Portanto, EPI foi construída em três versões: 1. infantil - as crianças respondem os itens sobre si mesmas; 2. para mães/pais - os progenitores respondem os itens sobre seus filhos; 3 . para professores - os docentes respondem os itens sobre seus alunos. Os itens para cada versão eram semelhantes, de forma que a única diferença entre as versões foi a adequação dos pronomes. Por exemplo, na versão infantil utilizou-se "eu", na versão para mães/pais utilizou-se "meu filho" e na versão para professores utilizou-se "meu aluno".

As respostas foram elaboradas em escala do tipo Likert de três pontos (sempre $=2$ pontos; às vezes $=$ 1 ponto; ou nunca $=0$ pontos), indicando a frequência dos comportamentos da criança em cada situação descrita. Caso apresentasse um modelo unifatorial, o escore total da escala corresponderia à soma final dos pontos, sendo o escore mínimo zero e o máximo 28. A construção dos itens pautou-se nos critérios propostos por Pasquali (1998), ou seja: clareza, tipicidade, simplicidade, amplitude e critério comportamental. A análise foi realizada por dois juízes (autores IP, PG) que revisaram de forma independente o material antes de sua aplicação. Posteriormente, foi realizada uma análise semântica por meio um estudo piloto com 25 participantes, sendo oito crianças entre seis e 11 anos, três meninas e cinco meninos, as mães. Além disso, foi aplicado em pais de seis crianças e três professoras (duas de escola pública e uma de particular) para avaliara a compreensão dos itens.

No estudo piloto, a EPI foi aplicada em participantes escolhidos por conveniência de proximidade e de disponibilidade. Tal etapa foi realizada nas residências dos participantes, em uma cidade de pequeno porte do interior do Paraná e na capital do estado. Os itens da escala foram lidos para os participantes, individualmente. Solicitou-se aos participantes que sinalizassem caso algum item, frase ou palavra estivesse pouco compreensível e dessem sugestões para melhorias. Caso houvesse apontamentos, os itens iriam ser reformulados posteriormente. Não houve sugestões para quaisquer itens nem por parte das crianças, de seus pais ou dos professores. Por isso, o formato final da EPI pode ser visualizado na Tabela 1.

Tabela 1

Itens da EPI após Análise Semântica

\begin{tabular}{|c|c|}
\hline Versão infantil & Versão para mães/pais e professores \\
\hline $\begin{array}{l}\text { 1. Quando chego a um lugar, cumprimento as pessoas que } \\
\text { conheço, como familiares, amigos e professores, dizendo, } \\
\text { por exemplo: oi, bom dia, boa noite, e aí, tudo bem, opa. }\end{array}$ & $\begin{array}{l}\text { 1. Expressa cumprimento de formas variadas (“oi”, } \\
\text { "e aí", "bom dia", "boa tarde”, "boa noite”, "tudo } \\
\text { bem?", "opa") quando encontra familiares, amigos, } \\
\text { professores, colegas. }\end{array}$ \\
\hline
\end{tabular}

2. Quando vou embora de algum lugar, me despeço das pessoas conhecidas, como familiares, amigos e professores, dizendo, por exemplo: tchau, até, valeu, falou, bom trabalho, boa aula, bom jogo.
2. Despede-se de familiares, amigos, e professores, de formas variadas ("até", "tchau", "valeu”, "falou”, "boa aula", "bom jogo", "bom trabalho"), ao ir embora ou sair de um local. 
Tabela 1 (continuação)

Itens da EPI após Análise Semântica

\section{Versão infantil}

3. Quando esbarro em familiares, amigos e

professores, derrubo algo, ou magoo essas pessoas, peço desculpas, dizendo, por exemplo: desculpa, foi sem querer, foi mal.

4. Quando familiares, amigos e professores me ajudam com alguma tarefa, ou me fazem um favor, agradeço, dizendo, por exemplo: obrigado, valeu.

5. Quando preciso passar e não tem espaço, quando preciso interromper alguém para falar, ou sair de um lugar, peço licença para a minha família, amigos e professores.

6. Faço elogios à minha família, amigos e professores quando gosto de algo que essas pessoas fizeram, dizendo, por exemplo: gostei, parabéns, achei bonito, achei legal.

7. Quando preciso de ajuda, peço por favor para os meus familiares, amigos ou professores.

8. Quando me apresentam alguém que eu não conhecia, cumprimento essa pessoa, dizendo, por exemplo: oi, bom dia, boa noite, e aí, tudo bem.

9. Quando vou embora de algum lugar, me despeço de pessoas que acabei de conhecer, dizendo, por exemplo: tchau, até, valeu.

10. Quando esbarro em pessoas que não conheço, derrubo algo, ou magoo essas pessoas, peço desculpas, dizendo, por exemplo: desculpa, foi sem querer, foi mal.

11. Quando funcionários, atendentes ou pessoas que não conheço me ajudam em algo ou me fazer um favor, agradeço, dizendo, por exemplo: obrigado, valeu.

12. Quando preciso passar e não tem espaço, quando preciso interromper alguém para falar, ou sair de um lugar, peço licença para pessoas que não conheço.

13. Faço elogios à pessoas que não conheço quando gosto de algo que essas pessoas fizeram, dizendo, por exemplo: gostei, parabéns, achei bonito, achei legal.

14. Quando preciso de ajuda, peço por favor a pessoas que não conheço.

Por fim, a EPI em suas três versões (infantil, para pais e para professores) foi submetida a uma análise semântica que referendou os itens inicialmente construídos, permitindo que se procedesse às análises psicométricas de seus itens. Posteriormente, verificaram-se as hipóteses de que as práticas parentais positivas correlacionariam positivamente com a polidez, e que as negativas correlacionariam negativamente com ela, por meio da correlação da EPI com o IEP.

\section{Estudo 2: Fidedignidade e Evidências de Validade da EPI}

Versão para mães/pais e professores

3. Pede desculpas de formas variadas ("desculpa", "foi mal", "foi sem querer") a amigos, familiares e professores quando esbarra em alguém, derruba algo, ou comporta-se de forma inadequada.

4. Agradece familiares, amigos e professores de formas variadas ("obrigado", "valeu") quando recebe algo ou tem um pedido atendido.

5. Pede licença a familiares, amigos e professores para passar, para interromper e falar, para ausentar-se.

6. Elogia amigos, familiares e professores quando algo lhe agrada, dizendo, por exemplo: "gostei", "parabéns", "achei bonito", "achei legal."

7. Pede "por favor" a familiares, amigos e professores quando solicita ajuda.

8. Expressa cumprimento de formas variadas ("oi", "e aí", "bom dia”, "boa tarde”, "tudo bem?”, “opa”) quando é apresentado a alguém desconhecido.

9. Despede-se de pessoas que acabou de conhecer de formas variadas ("até", "tchau", "valeu", "falou"), ao ir embora ou sair de um local.

10. Pede desculpas de formas variadas ("desculpa", "foi mal", "foi sem querer") a pessoas desconhecidas quando esbarra em alguém, derruba algo, ou comporta-se de forma inadequada.

11. Agradece pessoas desconhecidas de formas variadas ("obrigado", "valeu") quando recebe algo ou tem um pedido atendido.

12. Pede licença a pessoas desconhecidas para passar, para interromper e falar, para ausentar-se.

13. Elogia pessoas pouco próximas (funcionários, atendentes, conhecidos) quando algo lhe agrada, dizendo, por exemplo: "gostei”, "parabéns", "achei bonito", "achei legal."

14. Pede "por favor" a pessoas desconhecidas ou pouco próximas quando solicita ajuda.

\section{Participantes}

Nesta etapa, participaram 146 crianças entre sete e 11 anos de idade $(M=8,99 ; D P=1,46)$, cursando entre o segundo e o sexto ano do ensino fundamental $(M=4,10 ; D P=1,36)$, sendo $50,3 \%$ meninos $(n=74) \mathrm{e}$ $49,7 \%(n=72)$ meninas. Do total, 38 meninos e 39 meninas eram estudantes de escola pública, e 36 meninos e 33 meninas eram estudantes de escola privada.

Participaram ainda as mães de 136 crianças e os pais de 88 crianças. Quanto à escolaridade dos progenitores, verificou-se que os pais e as mães das crianças estudantes de escola pública possuem um nível de 
escolaridade menor que os pais e mães das crianças estudantes de escola privada. Tal dado é percebido tanto pela discrepância de progenitores que possuem somente nível de ensino fundamental (40,28\% das mães e $30,23 \%$ dos pais de crianças estudantes de escola pública, em detrimento a $14,06 \%$ das mães e $13,34 \%$ dos pais de crianças estudantes de escola privada), quanto pela discrepância de progenitores que possuem ensino superior $(11,11 \%$ das mães e $16,28 \%$ dos pais de crianças estudantes de escola pública, em detrimento a $40,63 \%$ das mães e $40 \%$ dos pais de crianças estudantes de escola privada).

Além disso, participaram desta pesquisa as professoras de todas as crianças, sendo 22 docentes, todas do sexo feminino, as quais responderam sobre as 146 crianças.

\section{Instrumentos}

Questionário sociodemográfico. Composto por questões que possuíam a função de caracterizar a amostra. As crianças responderam um questionário que continha as seguintes informações: nome, idade, sexo, escola (pública ou privada) e em que ano estava matriculada. Os progenitores e as professoras responderam um questionário que contemplava os seguintes dados: nome, escolaridade e profissão.

A Escala de Polidez Infantil em suas três versões (infantil, para mães/pais e para professores) construída no Estudo 1. A versão infantil da EPI é composta por 14 itens, de forma que uma assertiva é apresentada para a criança ler e, posteriormente, responder a frequência com que se comporta da maneira expressa na assertiva, sendo que as possibilidades de resposta são em formato de escala Likert de três pontos, sendo $0=$ nunca, $1=$ às vezes e $2=$ sempre. Por exemplo, a assertiva do item 1 é: "Quando chego a um lugar, cumprimento as pessoas que conheço, como familiares, amigos e professores, dizendo, por exemplo: "oi", "bom dia", "boa noite", "e aí", "tudo bem”, “opa”". Após ler esse item, a criança avalia a frequência com que pratica essa ação, escolhendo entre as três respostas a que melhor representar o que faz.

A versão da EPI para mães/pais também é composta por 14 itens, de forma que uma assertiva é apresentada para cada progenitor ler e, posteriormente, responder a frequência com que seu filho se comporta da maneira expressa na assertiva, sendo que as possibilidades de resposta são em formato de escala Likert de três pontos, sendo $0=$ nunca, $1=$ às vezes, e $2=$ sempre. Por exemplo, a assertiva do item 1 é: "Expressa cumprimento de formas variadas ("oi", "e aî", "bom dia", "boa tarde", "boa noite", "tudo bem?", "opa”) quando encontra familiares, amigos, professores, colegas". Após ler esse item, cada progenitor avalia a frequência com que seu filho se comporta dessa forma, escolhendo entre as três respostas a que melhor representa o que a criança faz.
A versão da EPI para professores é igualmente composta por 14 itens, de forma que uma assertiva é apresentada para o docente ler e, posteriormente, responder a frequência com que seu aluno se comporta da maneira expressa na assertiva, sendo que as possibilidades de resposta são em formato de escala Likert de três pontos, sendo $0=$ nunca, $1=$ às vezes, e $2=$ sempre. Por exemplo, a assertiva do item 1 é: "Expressa cumprimento de formas variadas ("oi", "e aí", "bom dia", "boa tarde", "boa noite", "tudo bem?”, "opa”) quando encontra familiares, amigos, professores, colegas.". Após ler esse item, o professor avalia a frequência com que seu aluno se comporta dessa forma, escolhendo entre as três respostas a que melhor representa o que a criança faz.

\section{Procedimentos}

A pesquisa foi realizada em quatro escolas do estado do Paraná, sendo duas públicas e duas particulares. Para cada condição, foi escolhida uma na região metropolitana e outra em cidade do interior. Solicitou-se autorização das escolas para a realização da pesquisa. Depois de concedidas as autorizações, o projeto foi encaminhado ao Comitê de Ética da Universidade Tuiuti do Paraná (parecer número 2.182.790). A coleta de dados foi realizada por cinco pesquisadoras devidamente treinadas (a primeira autora do presente artigo e quatro auxiliares de pesquisa graduandas de Psicologia). Após autorização das escolas, a coleta de dados dividiu-se em três fases:

Fase 1 - Coleta com as mães e pais. Foi enviado o Termo de Consentimento Livre e Esclarecido (TCLE) e a EPI versão para mães/pais para os responsáveis via agenda das crianças. As mães e pais que concordaram em participar e autorizaram a participação de seus filhos na etapa 2 assinaram o TCLE e responderam a EPI versão para mães/pais sobre seus filhos, em suas residências, e os devolveram à escola por meio da agenda. Nessa fase, os pais responderam por autorrelato e, como era autoaplicável, sem acompanhamento dos pesquisadores.

Fase 2 - Coleta com as crianças. Estipulou-se junto à escola as datas para aplicação da EPI versão infantil o TCLE. A EPI versão infantil foi aplicada individualmente em ambiente privado e silencioso, com o auxílio das pesquisadoras. Estas liam as declarativas da EPI e solicitavam que a criança escolhesse entre as alternativas do instrumento, fazendo o registro da escolha. O tempo médio para que cada crianças respondesse o instrumento inteiro foi de 10 minutos.

Fase 3 - Coleta com os professores. Os professores (das crianças que participaram da fase 2) que concordaram em participar da pesquisa assinaram o TCLE e responderam a EPI versão para professores sobre seus alunos participantes da pesquisa. A resposta era individual no período em que estava na escola e também foi autoaplicável, sem a presença de pesquisador. 


\section{Análise de Dados}

Nessa etapa da pesquisa, obtiveram-se os escores totais da EPI e das sete práticas parentais do IEP, conforme manual de correção (Gomide, 2006). Esses dados foram inseridos em um banco de dados e posteriormente analisados por meio dos softwares Statistical Package for the Social Sciences (SPSS - 19) e o software $R$ (R Core Team, 2017), além das funções implementadas pelos pacotes psych (Revelle, 2015) e MBESS (Dunn, Baguley, \& Brunsden, 2014).

Para análise dos dados, os itens da EPI foram tratados como variáveis ordinais de três pontos e considerados não paramétricos pela avaliação da distribuição investigada por meio dos testes de Shapiro-Wilk e K-S $(p<0,05)$. Os procedimentos de análise dos dados contaram com duas etapas: uma destinada às evidências de validade baseada na estrutura fatorial da EPI (análise fatorial exploratória da EPI) e a segunda em relação à correlação com variáveis externas (correlação com práticas parentais).

Para obtenção de evidências de validade, fez-se a avaliação da dimensionalidade do teste, por meio de análises fatoriais exploratórias dos eixos principais das correlações policóricas dos itens (Revelle, 2015). As quatro amostras deste estudo foram compostas por 146, 136, 88 e 22 respondentes. Há discussões acerca da quantidade mínima que a amostra precisa ser composta para que seja realizada a análise fatorial, todavia, postula-se que a quantidade é somente uma variável; em casos onde os itens são bem explicados pelos fatores, os erros amostrais são diminuídos (Damásio, 2012; MacCallum, Widaman, Zhang, \& Hong, 1999).

Para a escolha do número de fatores a serem retidos, foi utilizada a inspeção visual do screeplot (Cattell, 1966) e análises paralelas de Horn (Horn, 1965). Como a inspeção visual tende a sugerir poucos fatores e as análises paralelas sugerem fatores demais (Primi, Santos, John, \& De Fruyt, 2016), índices de ajustes provenientes do pacote psych do R foram utilizados na decisão final de escolha do modelo. Os índices de ajuste (valores de referência) considerados para a adequação dos modelos foram o Standardized Root Mean Residual (SRMR) e RMSEA (Root Mean Square Error of Aproximation) ambos com valores ideais próximos ou inferiores a 0,10 (Hair, Black, Babin, \& Anderson, 2014). Os itens foram retidos nos fatores em que tiveram maior carga fatorial e, em caso de carga cruzada, indicado para aquele que tem maior relação teórica com o fator extraído. Itens com cargas inferiores a $0,30 \mathrm{em}$ todos os fatores extraídos foram retirados da escala final.

Por fim, a avaliação da fidedignidade de cada uma das versões do instrumento foi realizada por meio da análise da consistência interna (coeficiente ômega) para cada fator extraído na análise fatorial sendo adotado um intervalo de confiança de $95 \%$ para esse valor extraído
(Dunn et al., 2014). Além disso, foram estimadas as correlações entre os fatores para cada uma das versões.

\section{Resultados}

As três versões da EPI, quais sejam: infantil, para pais/mães e para professores foram submetidas individualmente às análises psicométricas. Embora a versão da EPI para pais/mães seja a mesma, os parâmetros psicométricos foram calculados de forma individual para cada grupo. Primeiramente, comparou-se a média dos escores totais da EPI versão infantil, da versão respondida pelos progenitores (mãe e pai) e da versão respondida pelos professores, de acordo com o sexo e a idade das crianças. Por isso, foram realizadas análises considerando cada versão, mas agrupando os dados das diferentes faixas etárias e de gênero das crianças.

Para verificação da estrutura fatorial da EPI versão infantil, inicialmente realizou-se uma primeira análise fatorial, na qual dois itens (4 e 14) apresentaram cargas cruzadas e menores que 0,3 tanto no fator 1 quanto no fator 2. Portanto, optou-se por excluí-los da escala para uma nova análise. Na nova análise da EPI versão infantil, os fatores 1 e 2 permaneceram compostos pelos mesmos itens, e os índices de consistência interna dos fatores também permaneceram iguais. Apesar da variância explicada aumentar de 35\% para 38\% da primeira para a segunda análise e haver aumento na carga fatorial dos itens, a estrutura da escala da versão infantil precisa ser revisada.

Diferentemente da escala infantil, a Tabela 2 demonstrou que a matriz é fatorável tanto na versão respondida pelas mães $(\mathrm{KMO}=0,87)$ quanto na respondida pelos pais $(\mathrm{KMO}=0,88)$. Além disso, foi observado que os itens que compuseram os dois fatores foram os mesmos. Ou seja, tanto nas respostas das mães quanto nas respostas dos pais, o primeiro fator foi composto pelos itens $3,4,5,6,7,10,11,12,13$ e 14; já o segundo fator composto pelos itens 1, 2, 8 e 9. Cabe salientar, no entanto, que, na versão respondida pelas mães, os itens $3,4,8 \mathrm{e}$ 9 apresentaram cargas acima de 0,3 para ambos os fatores e foram inclusos nos fatores em que apresentaram carga maior. Já na escala respondida pelos pais os itens 1, 3, 6, 7, 11 e 14 apresentaram cargas acima de 0,3 para ambos os fatores e, assim como na versão, os itens foram inclusos nos fatores os quais apresentaram carga maior.

Por fim, a matriz da EPI versão para professores também foi considerada como fatorável $(\mathrm{KMO}=0,89)$. Dois fatores foram extraídos, sendo o primeiro composto pelos itens 3, 4, 5, 7, 10 e 12; e o segundo pelos itens 1 , $2,6,8,9,11,13$ e 14 . Os itens $6,9,11$ e 14 apresentaram cargas acima de 0,3 para ambos os fatores, contudo, os itens foram incluídos nos fatores os quais apresentaram carga maior. 
Tabela 2

Análises Fatoriais Exploratórias dos Eixos Principais das Correlações Policóricas com Rotação Oblimin, dos Itens da EPI nas Versões Infantil, para Mães, Pais e Professores

\begin{tabular}{|c|c|c|c|c|c|c|c|c|c|c|c|c|c|}
\hline \multirow{2}{*}{ Item } & \multirow{2}{*}{ Comportamento } & \multicolumn{3}{|c|}{$\begin{array}{l}\text { Versão } \\
\text { Infantil }^{1}\end{array}$} & \multicolumn{3}{|c|}{$\begin{array}{c}\text { Versão } \\
\text { para mães }\end{array}$} & \multicolumn{3}{|c|}{$\begin{array}{c}\text { Versão } \\
\text { para pais }\end{array}$} & \multicolumn{3}{|c|}{$\begin{array}{l}\text { Versão para } \\
\text { professores }^{4}\end{array}$} \\
\hline & & $\begin{array}{c}\text { Fator } \\
1\end{array}$ & $\begin{array}{c}\text { Fator } \\
2\end{array}$ & $\mathrm{R}^{2}$ & $\begin{array}{c}\text { Fator } \\
1\end{array}$ & $\begin{array}{l}\text { Fator } \\
2\end{array}$ & $\mathrm{R}^{2}$ & $\begin{array}{c}\text { Fator } \\
1\end{array}$ & $\begin{array}{c}\text { Fator } \\
2\end{array}$ & $\mathrm{R}^{2}$ & $\begin{array}{c}\text { Fator } \\
1\end{array}$ & $\begin{array}{c}\text { Fator } \\
2\end{array}$ & $\mathrm{R}^{2}$ \\
\hline 1 & $\begin{array}{l}\text { Cump. } \\
\text { Conhecidos }\end{array}$ & 0,47 & & 0,24 & & 0,86 & 0,73 & & 0,45 & 0,46 & & 0,98 & 0,87 \\
\hline 2 & Desp. Conhecidos & 0,75 & & 0,49 & & 0,76 & 0,67 & & 0,58 & 0,60 & & 0,96 & 0,85 \\
\hline 3 & $\begin{array}{l}\text { Desc. } \\
\text { Conhecidos }\end{array}$ & & 0,72 & 0,56 & 0,50 & & 0,54 & 0,53 & & 0,61 & 0,97 & & 0,78 \\
\hline 4 & $\begin{array}{l}\text { Agrad. } \\
\text { Conhecidos }\end{array}$ & - & - & - & 0,54 & & 0,59 & 0,63 & & 0,62 & 0,58 & & 0,67 \\
\hline 5 & $\begin{array}{l}\text { Solic. lic. } \\
\text { Conhecidos }\end{array}$ & & 0,30 & 0,18 & 0,48 & & 0,41 & 0,77 & & 0,50 & 0,93 & & 0,88 \\
\hline 6 & $\begin{array}{l}\text { Elog. } \\
\text { Conhecidos }\end{array}$ & 0,62 & & 0,36 & 0,61 & & 0,58 & 0,54 & & 0,60 & & 0,54 & 0,84 \\
\hline 7 & $\begin{array}{l}\text { Solic. favor } \\
\text { conhecidos }\end{array}$ & 0,43 & & 0,20 & 0,63 & & 0,46 & 0,43 & & 0,51 & 0,77 & & 0,85 \\
\hline 8 & $\begin{array}{l}\text { Cump. } \\
\text { Desconhecidos }\end{array}$ & 0,34 & & 0,19 & & 0,38 & 0,45 & & 0,60 & 0,53 & & 0,98 & 0,90 \\
\hline 9 & $\begin{array}{l}\text { Desp. } \\
\text { Desconhecidos }\end{array}$ & 0,53 & & 0,42 & & 0,47 & 0,65 & & 0,90 & 0,70 & & 0,54 & 0,78 \\
\hline 10 & $\begin{array}{l}\text { Desc. } \\
\text { Desconhecidos }\end{array}$ & & 0,72 & 0,53 & 0,83 & & 0,77 & 0,77 & & 0,72 & 0,75 & & 0,75 \\
\hline 11 & $\begin{array}{l}\text { Agrad. } \\
\text { Desconhecidos }\end{array}$ & 0,66 & & 0,53 & 0,78 & & 0,67 & 0,40 & & 0,71 & & 0,62 & 0,97 \\
\hline 12 & $\begin{array}{l}\text { Solic. lic. } \\
\text { Desconhecidos }\end{array}$ & & 0,71 & 0,47 & 0,97 & & 0,73 & 0,96 & & 0,75 & 0,97 & & 0,91 \\
\hline 13 & $\begin{array}{l}\text { Elog. } \\
\text { Desconhecidos }\end{array}$ & 0,59 & & 0,35 & 0,67 & & 0,57 & 0,61 & & 0,54 & & 0,73 & 0,78 \\
\hline 14 & $\begin{array}{l}\text { Agrad. } \\
\text { Desconhecidos }\end{array}$ & - & - & - & 0,63 & & 0,45 & 0,45 & & 0,46 & & 0,58 & 0,87 \\
\hline \multicolumn{2}{|c|}{ Índice Ômega $(\omega)$} & 0,68 & 0,52 & & 0,87 & 0,76 & & 0,88 & 0,73 & & 0,92 & 0,94 & \\
\hline \multicolumn{2}{|c|}{ Variância explicada } & & $38 \%$ & & $59 \%$ & & & $59 \%$ & & & $83 \%$ & & \\
\hline \multicolumn{2}{|l|}{$\mathrm{KMO}$} & & 0,67 & & 0,87 & & & 0,88 & & & 0,89 & & \\
\hline \multicolumn{2}{|c|}{ Teste de Bartlett } & & $p<0,05$ & & \multicolumn{3}{|c|}{$p<0,05$} & \multicolumn{3}{|c|}{$p<0,05$} & \multicolumn{3}{|c|}{$p<0,05$} \\
\hline
\end{tabular}

Nota. ${ }^{1}$ RMSEA $=0,10$, SRMS $=0,09$, correlação entre fatores $=0,37 ;{ }^{2}$ RMSEA $=0,1$, SRMS $=0,09$, correlação entre fatores $=0,53 ;{ }^{3} \mathrm{RMSEA}=0,07$, SRMS $=0,06$, correlação entre fatores $=0,59 ;{ }^{4} \mathrm{RMSEA}=0,04, \mathrm{SRMS}=0,03$, correlação entre fatores $=0,72$

\section{Discussão}

As evidências de validade do instrumento foram verificadas por meio de evidência baseada na estrutura interna, obtida por meio da análise fatorial (Pasquali, 2001; Primi, Muniz, \& Nunes, 2009). Quanto à estrutura interna, verificou-se que o melhor índice de ajuste para as três versões do instrumento consistiu em uma solução de dois fatores.

Em geral, os fatores extraídos foram organizados mais pelos comportamentos expressos (conteúdo do item), do que pela relação do comportamento com pessoas conhecidas ou desconhecidas. Essa divisão quanto ao conteúdo pode ser explicada pela diferenciação proposta por Gomide (2010) entre a polidez convencional e a polidez moral. Por exemplo, os comportamentos de cumprimentar e despedir-se de conhecidos e desconhecidos (itens 1,2,8 e 9) compõem um dos fatores da EPI versão para mães e um dos fatores da EPI versão para pais. Compreendeu-se que ambos os comportamentos têm relação com a polidez convencional, pois verifica-se que as mães e pais ensinam as crianças a cumprimentarem e despedirem-se antes mesmo destas aprenderem a falar, por meio do aceno de mãos. O cumprimento nesse 
caso não representa necessariamente a expressão de um comportamento moral e pode ser inclusive sem considerar a outra pessoa como estímulo discriminativo para a emissão do comportamento. Os demais comportamentos, como agradecer e pedir desculpas, estão relacionados a identificação mais clara da pessoa e dos objetivos ao emitir o comportamento pró-social, ou seja, a emissão está inteiramente relação a resposta do outro.

Da mesma forma, um dos fatores da EPI versão para professores foi composto pelos mesmos itens que expressam os comportamentos de cumprimentar e despedir-se de conhecidos e cumprimentar desconhecidos. A diferença observada é que esse fator abrangeu outros itens, os quais apresentaram carga cruzada, mas maiores para o fator em questão. Esses itens correspondem aos comportamentos de elogiar conhecidos e desconhecidos, despedir-se, agradecer e solicitar favor a desconhecidos. Dessa forma, a hipótese é que as mães, pais e professores considerem tais comportamentos (cumprimentar) como mais básicos do que o restante dos comportamentos expressos. Portanto, as três versões da EPI respondidas pelos adultos apresentam encaixe dos fatores em um robusto modelo teórico das quais originaram-se (Gomide, 2010). Essa adequação ao modelo pode ser considerada, em última instância, uma evidência da validade dessas versões. Além disso, os dados da fidedignidade dos fatores pelos índices ômega nessas escalas são bastante satisfatórios o que indica que essas versões são medidas fidedignas.

A EPI versão infantil foi a única escala que apresentou níveis de ajuste melhores e maior precisão com a exclusão de itens. Isso pode representar que, para as crianças, os itens 4 (agradecer conhecidos) e 14 (solicitar favor a desconhecidos) não são compreendidos como exemplo de polidez, visto que são orientadas pelos pais a não conversarem com estranhos. Os ajustes propostos melhoraram a variância explicada de $35 \%$ para $38 \%$. Uma alternativa para aumentar ainda mais esse índice é a reorganização da EPI versão infantil em um maior número de itens para cada comportamento, com declarativas mais específicas. Essa distinção entre a forma de adultos e a forma infantil da EPI pode estar relacionada com o fato de que as crianças podem não ter compreendido as declarativas como descrições de comportamentos polidos ou mesmo que, embora compreendam as declarativas, que os comportamentos avaliados não correspondem completamente ao conceito de polidez que dominam com essa idade. Apesar da exclusão de dois itens, ainda assim a EPI versão infantil, os dados de ajuste e de fidedignidade não são satisfatórios sugerindo que as modificações sejam implementadas.

Um dado importante sobre esse é a EPI infantil, quando revisada, ou a versão de pais e professores, poderá ser uma medida para avaliar o efeito de intervenções sobre as crianças, seja via psicoeducação dos pais, educacionais ou psicoterápicas. É bastante provável que a alta polidez reflita práticas parentais positivas que estão relacionadas ao desenvolvimento de habilidades sociais e comportamento moral (Del Prette \& Del Prette, 2008; Falcke et al., 2012; Gomide, 2006; Patias et al., 2012, 2013), e as práticas negativas estão relacionadas ao desenvolvimento de comportamento antissocial (Gomide, 2006; Patterson, Degarmo, \& Knutson, 2000; Patterson, Reid \& Dishion, 1992). Logo, cabe ressaltar a importância do investimento em práticas parentais positivas, pois a família enquanto parte importante do sistema social pode contribuir com a quebra de ciclos de violência (Cecconello, Antoni, \& Koller, 2003).

\section{Considerações Finais}

As pesquisas sobre polidez ainda são escassas, mas a importância do tema tem sido reconhecida, haja vista a possibilidade de tornar as relações mais agradáveis, por meio do incentivo às ações de gentileza (ComteSponville, 2009; Gomide, 2010). Abre-se, portanto, caminho para o fomento de novos estudos para melhor compreender a polidez infantil e para ensiná-la em programas escolares (Netto \& Gomide, 2016) e demais contextos sociais. Os escores fornecidos pela EPI, particularmente respondidas por adultos, demonstraram ter evidências de validade e também precisão, ao passo que esses dados demonstram a sua viabilidade e confiabilidade tanto na identificação dos déficits comportamentais, quanto na aferição dos resultados de programa de intervenção com enfoque nos comportamentos polidos. A versão infantil precisará passar por ajustes que foram identificados e sugeridos no presente estudo. Por fim, salienta-se que, ao desenvolver as versões da EPI, esta pesquisa contribui para um conjunto de ações que deve ser voltada ao ensino da polidez, uma vez que é porta de entrada para a expressão da moral (Comte-Sponville, 2009).

\section{Agradecimentos}

Não há menções.

\section{Financiamento}

A presente pesquisa não recebeu nenhuma fonte de financiamento sendo custeada com recursos dos próprios autores.

\section{Contribuições dos autores}

Todos os autores contribuíram substancialmente para a elaboração do delineamento da pesquisa, análise e interpretação dos dados, bem como, para a revisão textual e aprovação da versão final deste estudo. Especificamente, as autoras Isadora Ferreira Primo Moreira e Paula Inez Cunha Gomide participaram da redação inicial do estudo - conceitualização, investigação, visualização, as autoras Isadora Ferreira Primo Moreira, Paula Inez Cunha Gomide e o autor Murilo Ricardo Zibetti participaram da análise dos dados, e as autoras Isadora Ferreira Primo Moreira, Paula Inez Cunha Gomide e o autor Murilo Ricardo Zibetti participaram da redação final do trabalho 
- revisão e edição. Todos os autores assumem responsabilidade pública pelo conteúdo do manuscrito.

\section{Disponibilidade dos dados e materiais}

Todos os dados e sintaxes gerados e analisados durante esta pesquisa serão tratados com total sigilo devido às exigências do Comitê de Ética em Pesquisa em Seres
Humanos. Porém, o conjunto de dados e sintaxes que apoiam as conclusões deste artigo estão disponíveis mediante razoável solicitação ao autor principal do estudo.

\section{Conflito de interesses}

Os autores declaram que não há conflitos de interesses.

\section{Referência}

Binfet, J. T., Gadermann, A. M., \& Schonert-Reichl, K. A. (2016). Measuring Kindness at School: Psychometric properties of a School Kindness Scale for children and adolescents. Psychology in the Schools, 53(2), 111-126. doi: 10.1002/pits.21889

Cattell, R. B. (1966). The Scree Test for the Number of Factors. Multivariate Behavioral Research, 1(2), 245-276. doi: 10.1207/ s15327906mbr0102_10

Cecconello, A. M., De Antoni, C., \& Koller, S. H. (2003). Práticas educativas, estilos parentais e abuso físico no contexto familiar. Psicologia em estudo, 8(2), 45-54. doi: 10.1590/S1413-73722003000300007

Comte-Sponville, André. (2009). Pequeno tratado das grandes virtudes. 2 ed. São Paulo: Martins Fontes.

Damásio, B. F. Uso da análise fatorial exploratória em Psicologia. Avaliação Psicológica, 11(2), 213-228.

Del Prette, Z. A. P., \& Del Prette, A. (2008). Um sistema de categorias de habilidades sociais educativas. Paidéia, 18(41), 517-530. doi: 10.1590/S0103-863X2008000300008

Dishion, T. J., \& McMahon, R. J. (1998). Parental monitoring and the prevention of child and adolescent problem behavior: A conceptual and empirical formulation. Clinical child and family psychology review, 1(1), 61-75. doi: 10.1023/A:1021800432380

Dunn, T. J., Baguley, T., \& Brunsden, V. (2014). From alpha to omega: A practical solution to the pervasive problem of internal consistency estimation. British journal of psychology, 105(3), 399-412. doi: 10.1111/bjop.12046

Esteves, P. L. M. L. (1998). Cordialidade e familismo amoral: Os dilemas da modernização. Revista Brasileira de Ciências Sociais, 13(36). doi: $10.1590 / \mathrm{S} 0102-69091998000100006$

Falcão, A. P., \& Bolsoni-Silva, A. T. (2016). PROMOVE-Crianças - Treinamento de Habilidades Sociais. São Paulo: Hogrefe.

Falcke, D., Rosa, L. W. D., \& Steigleder, V. A. T. (2012). Estilos parentais em famílias com filhos em idade escolar. Gerais: Revista Interinstitucional de Psicologia, 5(2), 282-293. Recuperado de pepsic.bvsalud.org/pdf/gerais/v5n2/v5n2a08.pdf

Gehm, T. P. (2013). Reflexões sobre o estudo do desenvolvimento na perspectiva da Análise do Comportamento (Dissertação de Mestrado, Universidade de São Paulo). Biblioteca Digital da USP. https://teses.usp.br/teses/disponiveis/47/47132/tde-28062013-161959/pt-br.php

Gomide, P. I. C. (2006). Inventário de estilos parentais: Modelo teórico, manual de aplicação, apuração e interpretação. Petrópolis: Vozes.

Gomide, P. I. C. (2010). Comportamento moral: Uma proposta para o desenvolvimento das virtudes. Curitiba: Juruá.

Gomide, P. I. C., Mascarenhas, A. B, \& Rocha, G. V. M. (2017). Avaliação de uma intervenção para redução de comportamentos antissociais e aumento da escolarização em adolescentes de uma instituição de acolhimento. Acta Comportamentalia: Revista Latina de Análisis de Comportamiento, 25(1), 25-40. Recuperado de www.redalyc.org/pdf/2745/274550025002.pdf

Gomide, P. I. C., Primo, Â. P., Petruy, C. C., Ortiz, F. P., Muniz, J., de Oliveira, M. G., \& Immich, V. M. (2012). Comportamentos de polidez em sala de aula. Psicologia Argumento, 30(69), 359-368. doi: 10.7213/psicol.argum.5982

Hair, J. F., Black, W. C., Babin, B. J., \& Anderson, R. E. (2014). Multivariate Data Analysis (7th ed.). Harlow, UK: Pearson Education Limited.

Horn, J. L. (1965). A rationale and test for the number of factors in factor analysis. Psychometrika, 30(2), 179-185. doi: 10.1007/BF02289447

La Taille, Y. (2001). Desenvolvimento moral: A polidez segundo as crianças. Cadernos de Pesquisa, (114), 89-119. doi: 10.1590/S010015742001000300004

Leech, G. (2007). Politeness: Is there an East-West divide? Journal of Politeness Research. Language, Behaviour, Culture, 3(2), 167-206. doi: 10.1515/PR.2007.009

Löhr, S. S. (2003). Estimulando o desenvolvimento de habilidades sociais em idade escolar. Em Z. A. P. Del Prette \& A. Del Prette. Habilidades sociais, desenvolvimento e aprendizagem (pp. 293-310). Campinas: Alínea.

MacCallum, R. C., Widaman, K. F., Zhang, S., \& Hong, S. (1999). Sample size in factor analysis. Psychological methods, 4(1), 84-99. doi: http:// dx.doi.org/10.1037/1082-989X.4.1.84

Melo, M. H. S., \& Silvares, E. F. M. (2003). Grupo cognitivo comportamental com famílias de crianças com déficits em habilidades sociais e acadêmicas. Temas em Psicologia, 11, 122-133. Recuperado em 03 de dezembro de 2017, de http://pepsic.bvsalud.org/pdf/tp/v11n2/ v11n2a06.pdf

Netto, R., \& Gomide, P. I. C. (2016). Programa de comportamento moral na Educação Infantil. Em S. R. Souza, V. B. Haydu, \& C. E. Costa, Análise do Comportamento Aplicada ao Contexto Educacional. Londrina: EDUEL, v. 4, p. 38-68.

Pasquali, L. (1998). Princípios de elaboração de escalas psicológicas. Revista de Psiquiatria Clínica, 25, 206-213. Recuperado de http://www. honet.usp.br/ipq/revista/vol25/n5/conc255a.htm

Pasquali, L. (2001). Técnicas de exame psicológico - TEP: Manual. São Paulo: Casa do Psicólogo, 23.

Patias, N. D., Siqueira, A. C., \& Dias, A. C. G.. (2012). Bater não educa ninguém! Práticas educativas parentais coercitivas e suas repercussões no contexto escolar. Educação e Pesquisa, 38(4). doi: 10.1590/S1517-97022012000400013

Patias, N. D., Siqueira, A. C., \& Dias, A. C. G. (2013). Práticas educativas e intervenção com pais: A educação como proteção ao desenvolvimento dos filhos. Mudanças. Psicol Saúde, 21(1), 29-40. doi: 10.15603/2176-1019/mud.v21n1p29-40 
Patterson, G. R., DeGarmo, D. S., \& Knutson, N. (2000). Hyperactive and antisocial behaviors: Comorbid or two points in the same process? Development and psychopathology, 12(1), 91-106. doi: 10.1017/S0954579400001061

Patterson, G. R., Reid, J. B., \& Dishion, T. J. (1992). Antisocial boys (Vol. 4). Eugene: Castalia Pub Co.

Primi, R., Muniz, M., \& Nunes, C. H. S. S. (2009). Definições contemporâneas de validade de testes psicológicos. Em C. S. Hutz. Avanços e polêmicas em avaliação psicológica: em homenagem a Jurema Alcides Cunha. São Paulo: Casa do psicólogo, p. 243-265.

Primi, R., Santos, D., John, O. P., \& De Fruyt, P. (2016). Development of an Inventory Assessing Social and Emotional Skills in Brazilian Youth. European Journal of Psychological Assessment, 32(1), 5-16. doi: 10.1027/1015-5759

R Core Team. (2017). R: A language and environment for statistical computing. R Foundation for Statistical Computing, Vienna, Austria. Recuperado de http://www.R-project.org/

Revelle, W. (2015). Psych: Procedures for Personality and Psychological Research. Evanston, Illinois. Recuperado de http://cran.r-project.org/ package $=$ psych Version $=1.5 .8$

Stattin, H., \& Kerr, M. (2000). Parental monitoring: A reinterpretation. Child development, 71(4), 1072-1085. doi: 10.1111/1467-8624.00210

Tsakona, V. (2016). Teaching politeness strategies in the kindergarten: A critical literacy teaching proposal. Journal of Politeness Research, 12(1), 27-54. doi: 10.1515/pr-2015-0022

\section{Sobre os autores}

Isadora Ferreira Primo Moreira é Mestre em Psicologia Forense (Universidade Tuiuti do Paraná) e professora na Faculdade de Pato Branco.

Murilo Ricardo Zibetti é Doutor em Psicologia (Universidade Federal do Rio Grande do Sul) e professor na Universidade do Vale do Rio dos Sinos (Unisinos).

Paula Inez Cunha Gomide é Doutora em Psicologia (Universidade de São Paulo) e coordenadora do Mestrado em Psicologia Forense da Universidade Tuiuti do Paraná.

\section{Como citar este artigo}

Moreira, I. F. P., Zibetti, M. R., \& Gomide, P. I. C. et al. (2020). Construção e Estrutura Fatorial de uma Escala de Polidez Infantil. Avaliação Psicológica, 19(4), 351-360. http://dx.doi.org/10.15689/ap.2020.1904.15490.01 